\title{
Secondary prevention of coronary heart disease in elderly population of Turkey: A subgroup analysis of ELDERTURK study
}

\author{
Salih Kilic ${ }^{1}$, Mutlu Çagan Sümerkan ${ }^{2}$, Volkan Emren ${ }^{3}$, Lütfü Bekar ${ }^{4}$, Sinan Cersit ${ }^{5}$,
} Elif Tunc ${ }^{6}$, Gülay Gök ${ }^{7}$, Emine Altuntas ${ }^{8}$, Uğur Canpolat ${ }^{9}$, Umit Yasar Sinan ${ }^{10}$, Namık Özmen ${ }^{11}$, Mehdi Zoghi ${ }^{1}$; on behalf of ELDERTURK study investigators

${ }^{1}$ Department of Cardiology, Ege University Faculty of Medicine, Izmir, Turkey

${ }^{2}$ Department of Cardiology, Sisli Hamidiye Etfal Education and Research Hospital, Istanbul, Turkey

${ }^{3}$ Department of Cardiology, Afyonkarahisar State Hospital, Afyon, Turkey

${ }^{4}$ Department of Cardiology, Hitit University Corum Education and Research Hospital, Corum, Turkey

${ }^{5}$ Department of Cardiology, Kosuyolu Kartal Heart Training and Research Hospital, Istanbul, Turkey

${ }^{6}$ Department of Cardiology, Izmir Military Hospital, İzmir, Turkey

${ }^{7}$ Department of Cardiology, Mardin State Hospital, Mardin, Turkey

${ }^{8}$ Department of Cardiology, Bingol State Hospital, Bingol, Turkey

${ }^{9}$ Department of Cardiology, Hacettepe University Faculty of Medicine, Ankara, Turkey

${ }^{10}$ Department of Cardiology, Cardiology Institute of İstanbul University, Istanbul, Turkey

${ }^{11}$ Department of Cardiology, GATA Haydarpaşa Training Hospital, Istanbul, Turkey

\begin{abstract}
Background: Secondary prevention plays an important role after acute coronary event due to high risk of adverse events in elderly. In present study we aimed to evaluate the lifestyle, management of risk factors and medical treatment for secondary protection in elderly patients with known coronary heart disease (CHD).

Methods: ELDERTURK is a non-interventional, multi-centered, observational study, which included total of 5694 elderly patients (> 65 years) from 50 centers in Turkey. In this study elderly patients from the ELDERTURK population with known CHD were evaluated for cardiovascular risk factors, comorbidities and medication usage.

Results: A total of 2976 (52.3\% of study) out of 5694 patients included in the ELDERTURK study were evaluated. All had known CHD with a mean age of $73.4 \pm 6.2$ years and $60.3 \%$ were male. $13.0 \%$ of patients were smokers, $42.4 \%$ were overweight and $21.1 \%$ were obese. Only $23.6 \%$ of patients reported to do regular exercise, $73.4 \%$ had history of hypertension, $47.4 \%$ had dyslipidemia and $33.9 \%$ had diabetes mellitus. The rate of patients with systolic blood pressure $>140 \mathrm{mmHg}$ were $31.1 \%$ and only $13.9 \%$ of patients had a recommended $\leq 70 \mathrm{mg} / \mathrm{dL}$ level of low-density lipoprotein cholesterol. Antiplatelet, statin, beta-blocker and angiotensin-converting enzyme inhibitor/angiotensin receptor blocker usage was limited to $27.3 \%$.

Conclusions: The ELDERTURK study shows that many patients with CHD have a high prevalence of modifiable risk factors and unhealthy lifestyle. Apart from this, many patients are not receiving therapeutic intervention and as a consequence most were not achieving the recommended goals. (Cardiol J 2019; 26, 1: 13-19)
\end{abstract}

Key words: coronary disease, prevention, aging, drugs, treatment, epidemiology

Address for correspondence: Dr. Salih Kılıç, Nizip State Hospital, Gaziantep, Turkey, İzmir, Turkey, tel: +90 5555588341, e-mail: kilicsalihhh@gmail.com

Received: 4.09.2017 Accepted: 10.09.2017 


\section{Introduction}

The elderly population is rapidly increasing in Turkey as in all industrialized countries. The rate of population aged $\geq 65$ is expected to reach $10.2 \%$ in $2023,20.8 \%$ in 2050 [1]. In several studies, increasing age is a powerful predictor of both short-term and long-term mortality following acute myocardial infarction [2-4]. The prevalence and incidence of coronary heart diseases (CHD) are significantly increased in the elderly population due to increase of traditional risk factors and prevalence which is associated with aging due to increases of inflammation, endothelial dysfunction and atherosclerosis [3]. The presence of obstructive coronary artery disease at autopsy is $50 \%$ in elderly women and $70 \%$ to $80 \%$ in elderly men [5]. Secondary prevention is as important as acute treatment in patients with CHD. There is clear guidance for secondary protection with lifestyle changes, management of risk factors and appropriate drug therapy advice. However, guideline recommendations may not apply exactly in practical living. Especially recommendations which could be applied less in elderly patients due to polypharmacy, drug interactions and side effect concerns associated with difficulties in changing long-term habits [6].

In the present study the aim was to evaluate lifestyle, management of risk factors and medical treatment for secondary prevention in elderly patients with known CHD enrolled in the ELDERTURK study.

\section{Methods}

The design, conduct, and main results of the ELDERTURK (Frequency of cardiovascular diseases and drug use in the elderly Turkish population was followed up at cardiology clinics) in this study have been presented previously [7]. In brief, the ELDERTURK study was a non-interventional, multi-centered, observational study to provide national epidemiological data for the incidence of cardiovascular diseases, risk factors, comorbid diseases and drug usage among an elderly group ( $>65$ years of age) in Turkey. This study was performed with the Institutional Review Board protocol approval date 11/03/2015 and number 700 between March 2015 and December 2015. All patients 65 years and older who admitted to the inpatient and outpatient cardiology clinics with symptoms were enrolled in the study.

Study inclusion criteria were as follows:

- 65 years and older age;
— admitted to an outpatient clinic and were able to provide a medical history;

- gave written consent.

Study exclusion criteria were as followed:

- below 65 years old;

- not available to give a reliable medical history because of concomitant diseases;

- refusal to give written consent.

A total of 5694 patients from 73 centers around different parts of Turkey were included. In this study elderly patients from the ELDERTURK population with known CHD ( $\mathrm{n}=2976$; $52.3 \%$ of study) were included to evaluate cardiovascular risk factors, comorbidities and medication usage. CHD was defined as having a previous history of a coronary artery bypass graft (CABG) operation, percutaneous trans-luminal coronary angioplasty or stent, myocardial infarction, and stable coronary artery disease. Demographic information of the patients were recorded. The smoking habit was described as being an active smoker defined inclusion to the study. Participants who exercised were grouped as doing exercise less than $150 \mathrm{~min}$ or more than this per week. Patients who were newly diagnosed with diabetes mellitus (DM) or were already on anti-diabetic therapy were identified as diabetic. Hypertension was defined as taking anti-hypertensive therapy, diagnosed with hypertension or having a systolic blood pressure (SBP) $\geq 140 \mathrm{mmHg}$ and diastolic blood pressure (DBP) $\geq 90 \mathrm{mmHg}$ without diagnosis. The value of SBP $<140 \mathrm{mmHg}$ was the target value for blood pressure control as recommended by European Society of Cardiology (ESC) hypertension guidelines in patients with CHD [8]. Body mass index (BMI) was calculated by using weight $[\mathrm{kg}] /$ height $\left[\mathrm{m}^{2}\right]$ formula. Subjects were divided into four groups based on BMI: underweight $<18.5 \mathrm{~kg} / \mathrm{m}^{2}$; normal $18.5-24.9 \mathrm{~kg} / \mathrm{m}^{2}$; overweight $25-29.9 \mathrm{~kg} / \mathrm{m}^{2}$ and obese $\geq 30 \mathrm{~kg} / \mathrm{m}^{2}$ [9]. Total cholesterol, low-density lipoprotein cholesterol (LDL-C), high-density lipoprotein cholesterol (HDL-C), triglyceride and fasting blood glucose levels were recorded for each patient. Target values recommended by the ESC dyslipidemia guideline is LDL-C $\leq 70 \mathrm{mg} / \mathrm{dL}$ or $\mathrm{a} \geq 50 \%$ reduction from baseline LDL-C in patients with known CHD [10]. In this study target LDL-C level was $<70 \mathrm{mg} / \mathrm{dL}$.

\section{Statistical analysis}

All data were analyzed with SPSS (Statistical Package for the Social Sciences) software for Windows version 20.0. Continuous and quantitative data were summarized using descriptive statistics 
Table 1. Baseline characteristic features of patients.

\begin{tabular}{lcc}
\hline Features & N & $\begin{array}{c}\text { Mean } \pm \text { SD } \\
\text { or } \%\end{array}$ \\
\hline Age [years] & 2976 & $73.4 \pm 6.2$ \\
$\geq 80$ years & 541 & 18.2 \\
Male & 1794 & 60.3 \\
CABG & 837 & 28.1 \\
PTCA/stent & 1290 & 43.3 \\
Heart failure & 1128 & 37.9 \\
HFrEF & 681 & 22.9 \\
HFpEF & 447 & 15.0 \\
Dysrhythmia & 810 & 27.2 \\
Pacemaker & 116 & 3.9 \\
Prosthetic valve & 91 & 3.1 \\
Cigarette smoking & 388 & 13.0 \\
Exerciser & 704 & 23.6 \\
Exercise < 150 min/week & 357 & 12.0 \\
Exerciser $>$ 150 min/week & 347 & 11.7 \\
Hypertension & 2184 & 73.4 \\
Hyperlipidemia & 1412 & 47.4 \\
Diabetes mellitus & 1008 & 33.9 \\
Anemia & 508 & 17.1 \\
Pulmonary hypertension: & 508 & 17.1 \\
Primary & 8 & 0.3 \\
Secondary & 500 & 16.8 \\
Respiratory system disease & 596 & 20.0 \\
\hline CAB - coronay atery bypass & & \\
\hline
\end{tabular}

CABG - coronary artery bypass graft; HFrEF — heart failure with reduced ejection fraction; HFpEF - heart failure with preserved ejection fraction; PTCA - percutaneous transluminal coronary angioplasty; SD — standard deviation

including mean, standard deviations, medians (min-max), frequency distributions and percentages. Normality of data distribution was verified by Kolmogorov-Smirnov/Shapiro-Wilk test. Homogeneity of variance was assessed by Levene's test. Quantitative variables were compared with Student $t$ test or Mann-Whitney U test. P-values of $<0.05$ were considered statistically significant.

\section{Results}

Among 2976 patients with CHD, $60.3 \%$ were male, mean age was $73.4 \pm 6.2(65-94)$ years and $18.2 \%$ of patients $(\mathrm{n}=541)$ were $>80$ years old. Characteristic features of the patients are summarized in Table $1.43 .3 \%(\mathrm{n}=1290)$ of patients had a history of percutaneous transluminal coronary angioplasty/stent and $28.1 \%(\mathrm{n}=837)$ CABG. The number of patients diagnosed with heart failure was $1128(37.9 \%)$ and heart failure with reduced ejec-
Table 2. Laboratory values of study population.

\begin{tabular}{|c|c|}
\hline Feature & $\begin{array}{c}\text { Median } \\
\text { (min.-max.) }\end{array}$ \\
\hline BMI $\left[\mathrm{kg} / \mathrm{m}^{2}\right]$ & $27.2(14.6-58.8)$ \\
\hline $\begin{array}{l}\left.\text { Overweight (BMI } 25-29.9 \mathrm{~kg} / \mathrm{m}^{2}\right) \\
(\mathrm{n}=1261)\end{array}$ & $42.4 \%$ \\
\hline Obese $\left(\mathrm{BMI} \geq 30 \mathrm{~kg} / \mathrm{m}^{2}\right)(\mathrm{n}=628)$ & $21.1 \%$ \\
\hline $\mathrm{SBP}[\mathrm{mmHg}](\mathrm{n}=2636)$ & $130(70-220)$ \\
\hline $\mathrm{DBP}[\mathrm{mmHg}](\mathrm{n}=2636)$ & $80(25-122)$ \\
\hline $\mathrm{SBP}>140 \mathrm{mmHg}(\mathrm{n}=819)$ & $31.1 \%$ \\
\hline Heart rate $[\mathrm{bpm}]$ & 75 (32-169) \\
\hline Hemoglobin & $13(7-19)$ \\
\hline eGFR & $67.2(1-176)$ \\
\hline $\begin{array}{l}\text { Fasting blood glucose }[\mathrm{mg} / \mathrm{dL}] \\
(\mathrm{n}=2158)\end{array}$ & $105(35-502)$ \\
\hline Total cholesterol $(n=2203)$ & $181(76-514)$ \\
\hline LDL-C $(n=2288)$ & $106(10-422)$ \\
\hline LDL-C $<70 \mathrm{mg} / \mathrm{dL}(\mathrm{n}=318)$ & $13.9 \%$ \\
\hline Triglycerides [mg/dL] $(\mathrm{n}=2275)$ & $132(27-906)$ \\
\hline $\begin{array}{l}\mathrm{LDL}-\mathrm{C}<70 \mathrm{mg} / \mathrm{dL} \\
\mathrm{SBP}<140 \mathrm{mmHg}(\mathrm{n}=219)\end{array}$ & $9.6 \%$ \\
\hline
\end{tabular}

BMI — body mass index; DBP — diastolic blood pressure; eGFR estimated glomerular filtration rate; LDC-C — low density lipoprotein cholesterol; SBP — systolic blood pressure

tion fraction $(22.9 \%, \mathrm{n}=681)$ was more frequent. Patients who had a history of arrhythmia were reported at $27.2 \%(\mathrm{n}=810)$ and the most frequent arrhythmia was atrial fibrillation/flutter $(80 \%$, $\mathrm{n}=649) .13 .0 \%(\mathrm{n}=387)$ of patients were smokers and the ratio of male smokers $(19 \%, \mathrm{n}=334)$ was significantly higher than in the female smokers $(4.5 \%, \mathrm{n}=53)(\mathrm{p}<0.001)$. Hypertension $(73.4 \%$, $\mathrm{n}=2184)$ was the most frequent risk factor followed by hyperlipidemia $(47.4 \%, \mathrm{n}=1412)$ and diabetes mellitus $(33.9 \%, \mathrm{n}=1008)$. The mean BMI was $27.6 \pm 4.4 \mathrm{~kg} / \mathrm{m}^{2}$ (median $\left.27.2,14.6-58.8\right)$ and $42.4 \%(\mathrm{n}=1261)$ were overweight and $21.1 \%$ $(\mathrm{n}=628)$ were obese (Table 2). Seven hundred and four $(\mathrm{n}=704,23.6 \%)$ patients reported that they did regular exercise, but only a limited $11.7 \%$ ( $\mathrm{n}=347$ ) exercised more than $150 \mathrm{~min}$ or more per week. Median systolic and diastolic blood pressures were 130 (70-220) and 80 (25-122), respectively in patients whose blood pressures were recorded ( $\mathrm{n}=2636,88.5 \%$ of study population). The rate of patients with SBP $>140 \mathrm{mmHg}$ were $31.1 \%(n=819)$ among patients whose blood pressure was recorded (Table 2 ).

Additionally, among patients who had hypertension ( $\mathrm{n}=2184,73.4 \%$ of study population) the rate of patients with SBP $>140 \mathrm{mmHg}$ were re- 
Table 3. Pharmacological treatment.

\begin{tabular}{lcc}
\hline Drug treatment & $\mathbf{N}=2976$ & $\%$ \\
\hline Anti-platelet & 2360 & 79.3 \\
Anti-platelet-PPI & 1120 & 37.6 \\
DAPT & 559 & 18.8 \\
DAPT-PPI & 336 & 11.3 \\
Anticoagulant & 473 & 15.9 \\
Statin & 1485 & 49.9 \\
Beta-blocker & 2106 & 70.8 \\
ACEl/ARB & 2026 & 68.1 \\
PPI & 1368 & 46.0 \\
Anti-platelet-statin & 1331 & 44.7 \\
Anti-platelet-statin-beta- & 1045 & 35.1 \\
-blocker & & \\
Anti-platelet-statin-beta- & 812 & 27.3 \\
-blocker-ACE/ARB & & \\
\hline ACEl-anglensi-convetng enzme & & \\
\hline
\end{tabular}

ACEI - angiotensin-converting enzyme inhibitor; ARB angiotensin receptor blocker; DAPT — dual anti-platelet treatment; $\mathrm{PPI}$ - proton pump inhibitor

Table 4. Distribution of anti-platelet therapy.

\begin{tabular}{lcc}
\hline Medication & N & $\%$ \\
\hline Acetylsalicylic acid & 1501 & 63.6 \\
Clopidogrel & 290 & 12.2 \\
Acetylsalicylic acid: clopidogrel & 506 & 21.4 \\
Acetylsalicylic acid: ticagrelor & 48 & 2.0 \\
Acetylsalicylic acid: prasugrel & 5 & 0.2 \\
Prasugrel & 3 & 0.1 \\
Ticagrelor & 7 & 0.3 \\
Total & 2360 & 100 \\
\hline
\end{tabular}

ported as $33.9 \%(\mathrm{n}=739)$ and almost all $(\mathrm{n}=716$, $98.1 \%$ ) were receiving at least one anti-hypertensive agent. Similarly, the rate of hypertensive patients with at least one antihypertensive therapy was high at $97.5 \%(\mathrm{n}=2129)$. The median LDL-C value was $106(10-422) \mathrm{mg} / \mathrm{dL}$ in patients whose LDL-C was recorded (2288 patients; $76.9 \%$ ). Only $13.9 \%(\mathrm{n}=318)$ of patients had a LDL-C value of recommended $\leq 70 \mathrm{mg} / \mathrm{dL}$ level (Table 2 ). The recommendation level was reached in only $15.2 \%$ $(n=165)$ of patients with known hyperlipidemia similar to the entire population. Median LDL-C level was higher in patients with hyperlipidemia than non-hyperlipidemia or unknown patients (108 [30-422] mg/dL, 105 [10-281]; p = 0.002, respectively). The rate of statin use was $81.5 \%$ $(\mathrm{n}=1151)$ in patients with a history hyperlipi- demia and 49.9\% $(n=1485)$ in all patients. The rate of patients who met the recommendations of secondary prevention guidelines regarding both LDL-C level and SBP were 9.6\% $(\mathrm{n}=219)$. The rate of medication use in patients with known CHD are summarized in Table $3.79 .3 \%$ of patients $(\mathrm{n}=2360)$ were on anti-platelet treatment (Table 4). Approximately half of patients who were on antiplatelet treatment had concomitant use of proton pump inhibitors (PPI). This rate was slightly higher in patients who were receiving dual anti-platelet treatment. Concomitant use of anti-platelet and statin was limited to $44.7 \%(\mathrm{n}=1331)$ and combined anti-platelet, statin, beta-blocker usage was $35.1 \%$ ( $\mathrm{n}=1045)$ anti-platelet, statin, beta-blocker and angiotensin-converting enzyme inhibitor/angiotensin receptor blocker (ACEI/ARB) combination was used in $27.3 \%(\mathrm{n}=812)$.

\section{Discussion}

The assessment of elderly patients with CHD from the national epidemiologic study ELDERTURK has shown that most patients had hypertension, half had hyperlipidemia and one-third had DM. Almost half of the patients were overweight and one fifth of all patients were obese andonly one-quarter of patients did regular exercise. The number of patients with target SBP reduction and LDL-C reduction was low, elderly patients with known CHD were far from receiving appropriate secondary prevention.

The purpose of secondary prevention is to protect patients from major clinical events such as myocardial infarction and to reduce the progression of coronary heart disease. As in all developed economies the importance of secondary prevention in cardiovascular disease, which is increasing in Turkey and as well as in other elderly populations. In recent years, several randomized controlled studies, which demonstrate the importance of hypertension, hyperlipidemia, smoking, DM and antithrombotic treatment, have been published in secondary protection. Though it has been observed that a large part of elderly populations do not receive proven treatments in clinical practice [6].

Smoking is one of the major preventable risk factors for death [11, 12]. The EURIKA study in the Turkey group had an active smoking rate of $23.7 \%$, was close to $21.3 \%$ which is Europe's average rate [13]. The EUROASPIRE II study has been shown that at the time of the index event $87.7 \%$ of patient were smoking and at the interview $21 \%$ of patients continued to smoke [14]. In 
EUROASPIRE III study during index event $69.7 \%$ of all patients included and $73.1 \%$ of patients from Turkey were smokers [15]. Interviews after the index event, $23 \%$ of patients from Turkey and $17 \%$ of all patients continued smoking [16]. In the present study smoking rates were lower compared to EUROASPIRE II, III and EURIKA studies. This could be explained by patients age differences included in this study and by older patients who smoked less than younger patients. In the EUROASPIRE II $44 \%$ of patients were over 60 years old, this rate was $58.6 \%$ in the EUROASPIRE III study.

A sedentary life is the main cause of many chronic diseases, CHD being one of the first. Similarly, an increase in physical activity, independent from age, gender and ethnicity increases quality of life [17]. Though, the rate of regular exercise among older patients is known to be very low [11]. In the EUROASPIRE III study, $59.1 \%$ of patients in the Europe group and $48.6 \%$ of patients in the Turkey group increased physical exercise, but only $7.4 \%$ of the Turkish group reported intense physical activity (3-4 times a week for at least $20 \mathrm{~min}$ ) [16]. Inthe present study results are similar to the EUROASPIRE III study. It is believed that the reason for the major part of the patients not doing physical activity or only light physical activity is due to being old and having comorbidities. Overweight, one of the major problems of the modern world is one of the leading causes of CHD. In the EURIKA study the obesity rate of the Turkish group was $36.2 \%$ and $43.5 \%$ for all patients included [13]. This study shows that even after a serious event like CHD, life style changes such as regular exercise and losing weight is not easily achieved.

Hypertension is a risk factor that could affect all age groups as well as the elderly. Elderly populations have a high rate of hypertension and the Framingham study showed that lifelong risk is $90 \%$ $[2,18,19]$. In the EURIKA study, rate of hypertension was $66.5 \%$ in the Turkey group, whereas it was $72.7 \%$ in the whole study group. Ninetyfour percent of all patients were under treatment for hypertension and only $38.8 \%$ reached target blood pressure levels [13]. In EUROASPIRE II, EUROASPIRE III and EUROASPIRE III the Turkey group, rate of patients with hypertension was $89.9 \%, 81.4 \%$ and $75.2 \%$, respectively and after the index event. Interviews showed that $50 \%, 56 \%$ and $55.2 \%$ respectively did not reach target blood pressure levels [14-16]. In the present study the rate of hypertension is similar to that of other studies. However, the rate of patients that achieved target blood pressure level were higher than in previous studies. The reason for high rates of target blood pressure level achievement may be due to regular medical treatment and frequent follow-up.

The relationship between LDL-C level and cardiovascular events continue in elderly people, despite a reduction in total and LDL-C levels with age, especially after the seventh decade $[20,21]$. Although effectiveness of statins in elderly patients is demonstrated with published data, it is well known that a large number of patients do not receive this treatment at both discharge or at followup periods [20-22]. In the EURIKA study, the rate of dyslipidemia in Europe was 57.7\% whereas in Turkey it was significantly lower (34.5\%) and had the lowest rates of all countries. Though, $30.4 \%$ of dyslipidemic patients treated in Turkey group reached target LDL-C levels, this was lower than the $41.2 \%$ observed in Europe [13]. In the EUROASPIRE III study lowering total cholesterol level rate was $51.7 \%$ in the Turkey group and $48.9 \%$ in Europe [15]. Yet again, the use of statin rate after an index event was $65 \%$ in the Turkey group and $78.1 \%$ in Europe [16]. When compared to this study, both the rate of statin use and the number of patients that reached the target LDL-C levels were significantly lower than in this study. This could be explained by avoiding optimal drug use in the elderly by doctors due to polypharmacy, drug interactions and side effects. Also, in some patients the LDL-C level over $70 \mathrm{mg} / \mathrm{dL}$ might have reduced $\geq 50 \%$ from baseline, but if the baseline LDL-C level is not known it might have affected the number of patients reaching the target level proposed by ESC guidelines.

Diabetes is among the most important cardiovascular risk factors. In the EURIKA study, the rate of diabetes in the Turkey group was $31.4 \%$ and $24.4 \%$ in Europe [13]. In EUROASPIRE III study, the rate of diabetes in Turkish subjects was similar to all patients included $(33.6 \%$ and $34.8 \%$, respectively). In this study $34.7 \%$ of patients had diabetes, this result correlates with prior studies. Both in this study and in previous studies, an average of 1 in 3 patients with CHD or cardiovascular risk factors has DM.

The continuity of treatment during both at the acute stage and long-term is vitally important in CHD $[2,8]$. The EUROASPIRE II, III and Turkey group of EUROASPIRE III survey have reported that $85.9 \%, 90.5 \%$, and $91.4 \%$ of patients respectively received an anti-platelet drug, $62.9 \%, 79.8 \%$, and $73.8 \%$ of patients respectively received a betablocker, $38 \%, 70.9 \%$, and $69 \%$ of patients respectively received ACEIs after discharge. In this study 
$79.3 \%$ of patients received an anti-platelet drug, $70.8 \%$ received a beta-blocker and $68.1 \%$ received ACEI/ARB. A less significant use of anti-platelet drugs may be due to concerns about bleeding in elderly patients. Despite the proven effectiveness of beta-blocker and ACEI/ARB in treatment, usage rate was slightly different than in published data. The use of PPI with anti-platelet drug therapy is recommended in patients with high risk of bleeding and with the elderly. Approximately half of the present patients were not receiving PPI therapy. Refusing medication in the elderly, avoidance of polypharmacy and various concerns physicians may have caused not initiating this efficient treatment for this patient group.

\section{Limitations of the study}

The most important limitation of the present study is that there is no comparison group. For this reason the data was compared with previous studies in Turkey and multicentre studies including Turkish patients. Due to being a cross-sectional study, some baseline laboratory values were not known and the discharge treatment is another limitation. When baseline laboratory values were not known for LDL-C level of reduction could not be assessed. The patients were elderly and may have provided incomplete information.

\section{Conclusions}

In conclusion, according to available literature this is the first study to evaluate the lifestyle, management of risk factors and medical treatment for secondary prevention among elderly patients in Turkey. Elder Turk study has shown that many patients with CHD have high prevalence of modifiable risk factors and unhealthy lifestyle. In addition, many patients are not receiving therapeutic intervention and as a consequence most are not achieving the recommended goals. There is wide gap in implementation of evidence-based medicine in practice.

\section{Acknowledgements}

This trial was supported by Turkish Society of Cardiology.

\section{Conflict of interest: None declared}

\section{References}

1. Shireman TI, Howard PA, Kresowik TF, et al. Combined anticoagulant-antiplatelet use and major bleeding events in elderly atrial fibrillation patients. Stroke. 2004; 35(10): 2362-2367, doi:
10.1161/01.STR.0000141933.75462.c2, indexed in Pubmed: 15331796.

2. Roger VL, Go AS, Lloyd-Jones DM, et al. American Heart Association Statistics Committee and Stroke Statistics Subcommittee. Heart disease and stroke statistics - 2012 update: a report from the American Heart Association. Circulation. 2012; 125(1): e2-e220, doi: 10.1161/CIR.0b013e31823ac046, indexed in Pubmed: 22179539.

3. Alexander KP, Newby LK, Cannon CP, et al. American Heart Association Council on Clinical Cardiology, Society of Geriatric Cardiology. Acute coronary care in the elderly, part I: NonST-segment-elevation acute coronary syndromes: a scientific statement for healthcare professionals from the American Heart Association Council on Clinical Cardiology: in collaboration with the Society of Geriatric Cardiology. Circulation. 2007; 115(19): 2549-2569, doi: 10.1161/CIRCULATIONAHA.107.182615, indexed in Pubmed: 17502590.

4. Alexander KP, Newby LK, Armstrong PW, et al. American Heart Association Council on Clinical Cardiology, Society of Geriatric Cardiology, American Heart Association Council on Clinical Cardiology, Society of Geriatric Cardiology. Acute coronary care in the elderly, part I: Non-ST-segment-elevation acute coronary syndromes: a scientific statement for healthcare professionals from the American Heart Association Council on Clinical Cardiology: in collaboration with the Society of Geriatric Cardiology. Circulation. 2007; 115(19): 2549-2569, doi: 10.1161/CIRCULATIONAHA.107.182615, indexed in Pubmed: 17502590.

5. Williams MA, Fleg JL, Ades PA, et al. American Heart Association Council on Clinical Cardiology Subcommittee on Exercise, Cardiac Rehabilitation, and Prevention. Secondary prevention of coronary heart disease in the elderly (with emphasis on patients $>$ or $=75$ years of age): an American Heart Association scientific statement from the Council on Clinical Cardiology Subcommittee on Exercise, Cardiac Rehabilitation, and Prevention. Circulation. 2002; 105(14): 1735-1743, indexed in Pubmed: 11940556.

6. Ko DT, Mamdani M, Alter DA. Lipid-lowering therapy with statins in high-risk elderly patients: the treatment-risk paradox. JAMA. 2004; 291(15): 1864-1870, doi: 10.1001/jama.291.15.1864, indexed in Pubmed: 15100205.

7. Zoghi M, Özyüncü N, Özal E, et al. Frequency of cardiovascular diseases and drug use in Turkish elderly population followed up at cardiology clinics: the ELDERTURK study. Turkish Journal of Geriatrics/Türk Geriatri Dergisi. 2017; 20(2).

8. Mancia G, Fagard R, Narkiewicz K, et al. 2013 ESH/ESC Guidelines for the management of arterial hypertension. Blood Pressure. 2013; 22(4): 193-278, doi: 10.3109/08037051.2013.812549.

9. Çelik A, İzci S, Kobat MA, et al. WARFARIN-TR Study Collaborates. The awareness, efficacy, safety, and time in therapeutic range of warfarin in the Turkish population: WARFARIN-TR. Anatol J Cardiol. 2016; 16(8): 595-600, doi: 10.5152/AnatolJCardiol.2015.6474, indexed in Pubmed: 27004711.

10. Catapano A, Reiner Ž, Backer GDe, et al. ESC/EAS Guidelines for the management of dyslipidaemias. Atherosclerosis. 2011; 217(1): 3-46, doi: 10.1016/j.atherosclerosis.2011.06.028.

11. Fleg JL, Forman DE, Berra K, et al. American Heart Association Committees on Older Populations and Exercise Cardiac Rehabilitation and Prevention of the Council on Clinical Cardiology, Council on Cardiovascular and Stroke Nursing, Council on Lifestyle and Cardiometabolic He. Secondary prevention of atherosclerotic cardiovascular disease in older adults: a scientific statement from the American Heart Association. Circulation. 2013; 
128(22): 2422-2446, doi: 10.1161/01.cir.0000436752.99896.22, indexed in Pubmed: 24166575.

12. Gellert C, Schöttker B, Brenner H. Smoking and all-cause mortality in older people: systematic review and meta-analysis. Arch Intern Med. 2012; 172(11): 837-844, doi: 10.1001/archinternmed.2012.1397, indexed in Pubmed: 22688992.

13. Banegas JR, López-García E, Dallongeville J, et al. Achievement of treatment goals for primary prevention of cardiovascular disease in clinical practice across Europe: the EURIKA study. Eur Heart J. 2011; 32(17): 2143-2152, doi: 10.1093/eurheartj/ehr080, indexed in Pubmed: 21471134.

14. EUROASPIRE II Study Group. Lifestyle and risk factor management and use of drug therapies in coronary patients from 15 countries; principal results from EUROASPIRE II Euro Heart Survey Programme. Eur Heart J. 2001; 22(7): 554-572, doi: 10.1053/euhj.2001.2610, indexed in Pubmed: 11259143.

15. Kotseva K, Wood D, De Backer G, et al. EUROASPIRE Study Group. EUROASPIRE III: a survey on the lifestyle, risk factors and use of cardioprotective drug therapies in coronary patients from 22 European countries. Eur J Cardiovasc Prev Rehabil. 2009; 16(2): 121-137, doi: 10.1097/HJR.0b013e3283294b1d, indexed in Pubmed: 19287307.

16. Tokgözoğlu L, Kaya EB, Erol Ç, et al. EUROASPIRE III: Türkiye ile Avrupa'nın karşılaştırılması. Türk Kardiyol Dern Arş. 2010; 38(3): 164-72.

17. Thompson PD, Buchner D, Pina IL, et al. American Heart Association Council on Clinical Cardiology Subcommittee on Exercise, Rehabilitation, and Prevention, American Heart Association Council on Nutrition, Physical Activity, and Metabolism Subcommittee on Physical Activity. Exercise and physical activity in the prevention and treatment of atherosclerotic cardiovascular disease: a statement from the Council on Clinical Cardiology (Subcommittee on Exercise, Rehabilitation, and Prevention) and the Council on Nutrition, Physical Activity, and Metabolism (Subcommittee on Physical Activity). Circulation. 2003; 107(24): 3109-3116, doi: 10.1161/01.CIR.0000075572.40158.77, indexed in Pubmed: 12821592.

18. Lloyd-Jones DM, Evans JC, Levy D. Hypertension in adults across the age spectrum: current outcomes and control in the community. JAMA. 2005; 294(4): 466-472, doi: 10.1001/ jama.294.4.466, indexed in Pubmed: 16046653.

19. Aronow WS, Fleg JL, Pepine CJ, et al. ACCF/AHA 2011 expert consensus document on hypertension in the elderly: a report of the American College of Cardiology Foundation Task Force on Clinical Expert Consensus documents developed in collaboration with the American Academy of Neurology, American Geriatrics Society, American Society for Preventive Cardiology, American Society of Hypertension, American Society of Nephrology, Association of Black Cardiologists, and European Society of Hypertension. J Am Coll Cardiol. 2011; 57(20): 2037-2114, doi: 10.1016/j.jacc.2011.01.008, indexed in Pubmed: 21524875.

20. Wong ND, Wilson PW, Kannel WB. Serum cholesterol as a prognostic factor after myocardial infarction: the Framingham Study. Ann Intern Med. 1991; 115(9): 687-693, indexed in Pubmed: 1929036.

21. Lewington S, Whitlock G, Clarke R, et al. Prospective Studies Collaboration. Blood cholesterol and vascular mortality by age, sex, and blood pressure: a meta-analysis of individual data from 61 prospective studies with 55,000 vascular deaths. Lancet. 2007; 370(9602): 1829-1839, doi: 10.1016/S0140-6736(07)61778-4, indexed in Pubmed: 18061058.

22. Shepherd J, Blauw GJ, Murphy MB, et al. PROSPER Group. Pravastatin in elderly individuals at risk of vascular disease (PROSPER): a randomised controlled trial. Lancet. 2002; 360(9346): 1623-1630. 